\title{
Comparison of female sexual function and sexual function of their partners between groups of pregnant and non-pregnant women
}

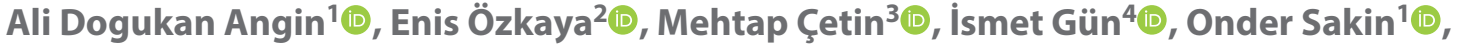

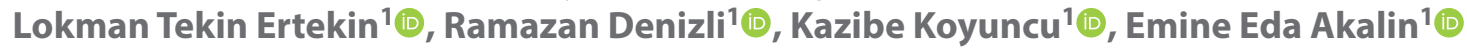 \\ ${ }^{1}$ Department of Obstetrics and Gynecology, Health Sciences University Kartal Training and Research Hospital, Istanbul, Turkey \\ ${ }^{2}$ Department of Obstetrics and Gynecology, Health Sciences University Zeynep Kamil Women and Children's Diseases Training \\ and Research Hospital, Istanbul, Turkey \\ ${ }^{3}$ Department of Obstetrics and Gynecology, Burhaniye State Hospital, Balıkesir, Turkey \\ ${ }^{4}$ Department of Obstetrics and Gynecology, Near East University, Faculty of Medicine, Nicosia, Cyprus
}

\begin{abstract}
Objectives: To compare the female sexual function index and sexual function of their partners between groups of pregnant and non-pregnant Turkish women.

Material and methods: This was a cross-sectional study of 321 women, including 252 healthy pregnant and 69 healthy nonpregnant women. Assessment of female sexual function index (FSFI), ARIZONA scores of their partners were compared in relation to some of the sociodemographic characteristics and pregnancy trimesters.

Results: Comparison of the groups revealed a significantly higher FSFI score in the non-pregnant group whereas the ARIZONA score was significantly higher in the pregnant group $(p<0.001)$. Age, gravidity, parity and smoking rate adjusted mean differences of scores remained statistically significant $(p<0.001)$. Higher ARIZONA $(>11)$ score rate was significantly higher in pregnant groups $(55.6 \%$ vs $23.2 \%, \mathrm{p}<0.001)$. Pregnancy was a risk factor for high ARIZONA score [OR: 4.1 (95\% $\mathrm{Cl} 2.2-7.6, \mathrm{p}<0.001)]$. Lower FSFI score rate was significantly higher in the pregnant group $(26.4 \% \mathrm{vs} 69.4 \%, \mathrm{p}<0.001)$. Pregnancy was a risk factor for low FSFI score [OR: 6.4 (95\% Cl 3.5-11.7, p < 0.001)].

Conclusions: Both female sexual function index and ARIZONA scores of their partners were found to be significantly different between groups of pregnant and nonpregnant Turkish women which indicated altered sexual function of couples during pregnancy.
\end{abstract}

Key words: female sexual function index; ARIZONA score; pregnancy; partner

Ginekologia Polska 2020; 91, 5: 235-239

\section{INTRODUCTION}

The female sexual response cycle is divided into four stages, including desire, arousal (excitement), orgasm, and dissolution [1]. Regarding these stages, women may experience different forms of sexual dysfunction such as lack of sexual desire, aroused arousal, and inaccessibility to orgasm and pain during sexual activity [1]. It is a multifactorial and underestimated problem with a prevalence of 20-50\% in general [2]. Cayan et al. [3] evaluated women aged 18-65 years and found that the prevalence of sexual dysfunction in Turkish women was $46.9 \%$. In literature, a significant decrease in sexual activities has been shown during pregnancy with increased gestational weeks [4]. The reasons suggested by this decline in sexual activity during pregnancy are physical discomfort, fear of harm to the baby, loss of interest, physical oddity, painful coitus, and lack of perceived attraction [5]. On the other hand in a previous study from Turkey, it was shown that The FSFI total scores were not significantly different between the pregnant and nonpregnant women. The study showed significant correlations between the total testosterone and androstenedione levels and sexual function [6]. The sexual function of male 
partners has been assessed by the ARIZONA scoring questionnaire, the reliability and validity of the ARIZONA scoring in the Turkish language were displayed by Soykan et al. [7]. The Turkish version of the ASEX-Female was shown to have good validity and reliability with good internal consistency (Cronbach's alpha $=0.89$ ). The correlation coefficient was 0.53 for the validity analysis and the cutoff point was 11 for the ROC analysis, which is highly discriminative in terms of validity criteria.

Female sexual dysfunction (FSD) is thought to be a public health problem affecting couples' quality of life. Pregnancy is a special time that involves physical, psychological and hormonal changes that affect women's sexual lives. However, sexual changes during pregnancy and their relationship to their partners' sexual quality require further investigation.

Therefore, the aim of this study was to compare the female sexual function index and sexual function of their partners.

\section{MATERIAL AND METHODS}

\section{Subjects}

This was a cross-sectional study of 321 women, including 252 healthy pregnant and 69 healthy nonpregnant Turkish women. Female sexual function index (FSFI) and ARIZONA score of their partners were compared in relation to some of the sociodemographic characteristics that were assessed at the Department of Obstetrics and Gynecology in Kartal Training and Research Hospital Obstetrics and Gynecology Clinics and Burhaniye State Hospital between February 2018 and April 2019. The study was conducted with sexually active participants aged 18-41 (married and reported having had sexual intercourse during the previous 4 weeks). The main exclusion criterion is the exclusion of pregnant women with abnormal continuing pregnancies, including the risk of miscarriage, preterm labor, and hypertensive disorder. Pregnant women were informed about pregnancy sexuality in the pregnancy education outpatient clinic in the same hospital and their questions were answered by a midwife. They were informed that sexual intercourse is safe during pregnancy, except in cases of pain, cramping, unexplained vaginal bleeding, early cervical dilatation, and early membrane rupture. Patient information forms and self-reported questionnaires were given to the patients who wanted to participate.

\section{Design}

This is a cross-sectional observational study in which the author collected data over a period of 15 months. Participants filled out self-reported questionnaires, including the Female Sexual Function Index (FSFI), and questions about their sociodemographic data and the ARIZONA survey was
Table 1. Coefficients for each item of FSFI scoring system

\begin{tabular}{|l|l|l|}
\hline Domain & Item number & Coefficient \\
\hline Desire & 1,2 & 0.6 \\
\hline Arousal & $3,4,5,6$ & 0.3 \\
\hline Lubrication & $7,8,9,10$ & 0.3 \\
\hline Orgasm & $11,12,13$ & 0.4 \\
\hline Satisfaction & $14,15,16$ & 0.4 \\
\hline Pain & $17,18,19$ & 0.4 \\
\hline
\end{tabular}

completed by the male partner of each female participant. Answers of the questionnaire on sociodemographic data were obtained regarding educational background, occupational status, income, medical history and gravity, parity, abortion, vaginal births, and cesarean section. Education was classified as years 8 years (primary and secondary) and more than 8 years (high school and university). All participants were married. Ethical approval was given by the Kartal Education and Research Hospital of Health Sciences University.

\section{Main Outcome Measures}

Sexual function was measured by FSFI, a 19-item self-administered questionnaire that assessed sexual function with six domains over the past four weeks: desire, arousal, lubrication, orgasm, satisfaction, and pain. Rosen et al. [8] developed a self-reported questionnaire to assess female sexual function. Turkey's FSF verification was done previously [9]. Questions 1,2,15 and 16 are scored between 1 and 5, while all other questions are scored between 0 and 5 . The total score of each area obtained from the related questions is multiplied by the coefficient factor (Tab. 1). The total score of all women with a total score below 25 were considered to have sexual dysfunction [10]. To assess sexual dysfunction in the male partner, we used the Arizona Sexual Experience Scale (ASEX), an approved five-item self-assessment scale that measures five major aspects of sexuality: 1) sex drive, 2) sexual arousal, 3) vaginal lubrication (in women) or penile erection. (males), 4) ability to reach orgasm and 5) satisfaction with orgasm. Each item gets scores between 1 and 6, total scores 5-30 and higher results indicate more sexual dysfunction. Total score $>11$ was considered to be sexual dysfunction [11]. Pregnancy was grouped as the first (0-13 weeks), second (14-26), and third (27-40 weeks) trimesters.

\section{Statistical Analysis}

The statistical parameters were computed using the Statistical Package for the Social Sciences version 21.0 (SPSS Inc., Chicago, IL, USA). The continuous variables were ex- 
pressed as the mean \pm standard deviation. The categorical variables were expressed as the number and percentage. The Mann-Whitney $\mathrm{U}$ test was used in the comparison between the averages of two groups. The Kruskal-Wallis test was used to compare more than two continuous variables. Adjusted means were compared by ANCOVA. Multivariate regression analysis was used to assess adjusted associations. Statistical significance was defined as $p<0.05$.

\section{RESULTS}

There was a significant difference between groups in terms of mean age of female partners $(p<0.05)$ however mean BMI, money income and mean age of male partners were similar ( $p>0.05)$ (Tab. 2). Gravidity ( 0.5 vs 1.8, $p<0.001)$ and parity ( 0.4 vs $0.6, p=0.028$ ) were significantly different between the groups. No difference was determined between the two groups in terms of rates of the route of previous deliveries $(p>0.05)$. No difference was observed between the two groups in terms of systemic disorder ( $p>0.05$ ). Educational status was also similar between pregnant and nonpregnant groups and groups of women with and without FSFI $<25$ ( $p>0.05)$. The smoking rate was significantly higher in the non-pregnant group ( $17.4 \%$ vs $8.3 \%, p=0.028)$. Adjusted and unadjusted means of ARIZONA and FSFI scores were shown in Table 2. A comparison of the groups revealed

\begin{tabular}{|c|c|c|c|c|c|}
\hline & Groups & $\mathbf{N}$ & Mean & $\begin{array}{l}\text { Std. } \\
\text { Deviation }\end{array}$ & $\begin{array}{l}p \\
\text { value }\end{array}$ \\
\hline \multirow{2}{*}{ Age [years] } & Non-pregnant & 69 & 28.4 & 6.01 & \\
\hline & Pregnant & 252 & 26.6 & 5.06 & 0.013 \\
\hline \multirow{2}{*}{ BMI $\left[\mathrm{kg} / \mathrm{m}^{2}\right]$} & Non-pregnant & 69 & 24.7 & 4.9 & \\
\hline & Pregnant & 252 & 26.4 & 12.6 & 0.26 \\
\hline \multirow{2}{*}{ Income } & Non-pregnant & 69 & 1.8 & 0.7 & \\
\hline & Pregnant & 252 & 1.9 & 0.6 & 0.177 \\
\hline \multirow{2}{*}{$\begin{array}{l}\text { Age of partner } \\
\text { [years] }\end{array}$} & Non-pregnant & 69 & 31.8 & 6.8 & \\
\hline & Pregnant & 252 & 30.7 & 5.3 & 0.235 \\
\hline
\end{tabular}

a significantly higher FSFI score in the non-pregnant group whereas the ARIZONA score was significantly higher in the pregnant group $(p<0.001)$ (Tab. 3). Age, gravidity, parity and smoking rate adjusted mean of scores remained statistically significant $(p<0.001)$. Higher ARIZONA (> 11) score rate was significantly higher in pregnant groups $(55.6 \%$ vs $23.2 \%$, $\mathrm{p}<0.001)$. Pregnancy was a risk factor for high ARIZONA score [OR: 4.1 (95\% Cl 2.2-7.6, p < 0.001)]. Lower FSFI score rate was significantly higher in the pregnant group (26.4\% vs $69.4 \%, p<0.001)$. In multivariate regression analysis pregnancy was found to be significantly associated with FSFI score $<25$ (beta coefficient $=0.321, p<0.001$ ) after adjustment for the age, gravidity and smoker rates. Pregnancy was a risk factor for low FSFI score [OR:6.4 (95\% CI 3.5-11.7, $\mathrm{p}<0.001)]$. A comparison of scores in relation to the three trimesters revealed no statistically significant difference $(p>0.05)$ (Tab. 4).

\section{DISCUSSION}

In the current study, which was performed with a sample of pregnant women, we found that the male partner sexual dysfunction (ARIZONA $>11$ ) rate was higher in the pregnant group (55.6\% vs $23.2 \%$, $\mathrm{p}<0.001$ ). Pregnancy was a risk factor for high ARIZONA score [OR: 4.1 (95\% Cl 2.2-7.6, p < 0.001)]. Lower FSFI score rate was significantly higher in the pregnant

\begin{tabular}{|c|c|c|c|c|c|}
\hline \multicolumn{2}{|l|}{ Trimesters } & $\mathbf{N}$ & Mean & $\begin{array}{l}\text { Std. } \\
\text { Deviation }\end{array}$ & $\begin{array}{l}\mathbf{p} \\
\text { value }\end{array}$ \\
\hline \multirow{4}{*}{$\begin{array}{l}\text { FSFI Total } \\
\text { Score }\end{array}$} & First & 72 & 19.4 & 9.8 & \\
\hline & Second & 96 & 19.4 & 8.9 & 0.141 \\
\hline & Third & 84 & 16.4 & 10.5 & \\
\hline & Total & 252 & 18.4 & 9.8 & \\
\hline \multirow{4}{*}{$\begin{array}{l}\text { ARIZONA } \\
\text { Total Score }\end{array}$} & First & 72 & 12.6 & 4.3 & \\
\hline & Second & 96 & 11.9 & 3.6 & 0.446 \\
\hline & Third & 84 & 11.8 & 3.1 & \\
\hline & Total & 252 & 12.1 & 3.7 & \\
\hline
\end{tabular}

\begin{tabular}{|l|l|l|l|l|l|}
\hline \multicolumn{2}{|c|}{ Table 3. Comparison summary of adjusted and unadjusted mean score values of pregnant and non-pregnant women } \\
\hline & Groups & N & Mean & Std. Deviation & p value \\
\hline \multirow{2}{*}{ FSFI Total Score } & Non-pregnant & 69 & 27.4 & 4.7 & $<0.001$ \\
\hline & Pregnant & 252 & 18.5 & 9.8 & \\
\hline $\begin{array}{l}\text { Age, Gravidity, Smoker Rate } \\
\text { Adjusted FSFI Total Score }\end{array}$ & Non-pregnant & 69 & 27.5 & 1.3 (SE) & $<0.001$ \\
\hline ARIZONA Total Score & Pregnant & 252 & 18.5 & 0.6 (SE) & $<0.001$ \\
\hline $\begin{array}{l}\text { Age, Gravidity, Smoker Rate } \\
\text { Adjusted Arizona Total Score }\end{array}$ & Non-pregnant & 69 & 9.2754 & 2.71642 & \\
\hline & Pregnant & 252 & 12.1349 & 3.72106 & 0.5 (SE) \\
\hline
\end{tabular}


group ( $26.4 \%$ vs $69.4 \%, p<0.001)$. Pregnancy was a risk factor for low FSFI score [OR: $6.4(95 \% \mathrm{Cl} 3.5-11.7, \mathrm{p}<0.001)]$. A comparison of scores in relation to the three trimesters revealed no statistically significant difference. In our literature search, we encountered several studies and reviews on this issue, in one of these reviews, one hundred thirty-five studies were systematically reviewed. Ninety-five of these studies were evaluated in more detail in a meta-analysis. The prevalence of female sexual dysfunction in premenopausal women was estimated to be $40.9 \%$. The prevalence rates of individual sexual disorders range from $20.6 \%$ (lubrication difficulties) to $28.2 \%$ (hypoactive sexual desire disorder). The results show that female sexual dysfunction is a major public health problem affecting $41 \%$ of premenopausal women in the world [12]. On the other hand, there are also several studies on specific populations especially the pregnant women, Ninivaggio et al. evaluated the sexual function of 623 nulliparous pregnant women using FSFI in the first, second and early third trimesters [13]. Authors reported sexual dysfunction rates of $36.3 \%$ in the first trimester, $36.8 \%$ in the second trimester, and $57 \%$ in the third trimester, and reported that mean FSFI scores decreased as the pregnancy progressed. The higher rate was reported in another study, Seven et al. [14] assessed pregnant Turkish women, sexual dysfunction rate was $77.6 \%$ in their study. In another study on Turkish pregnant women, Eryilmaz et al. showed $81.5 \%$ of sexual dysfunction during pregnancy. In their study with 238 Turkish pregnant women, significant relationships between changes were reported in sexual life during pregnancy and marriage duration, educational level, parity, and gravidity [15]. Consistently, Erol et al. [16] and Çorbacıoğlu et al. [17] conducted their studies on In Turkish pregnant women, both studies noted lower sexual function scores in women in the third trimester of their pregnancies compared with those in their first two trimesters of pregnancy. Pregnancy, especially in the third trimester, was found to have an impact on sexual health and decreased sexual function during pregnancy $[16,18]$. No differences were determined among different pregnancy trimesters in terms of either score in our study, higher mean total FSFI scores were observed in the first and second trimester but the difference did not reach statistical significance (19.5, 19.5 and 16.5 respectively).

Educational status was found to have a significant impact on sexual function, women having been trained for more than 8 years the low risk of sexual dysfunction compared to women who have been trained for 8 years or less [6]. Educational status was similar between pregnant and nonpregnant groups and groups of women with and without FSFI $<25$ or with and without ARIZONA score $>11(p>0.05)$ in our study population. Based on knowledge about sexual dysfunction in the third trimester, postpartum sexual function was assessed in a study; breastfeeding and poor partnership quality have emerged as important risk factors for postpartum sexual dysfunction problems. Depressive symptoms with cesarean section and high maternal education were correlated with dysfunctional problems in many sub-areas. The findings showed that women at risk for female sexual dysfunction were significantly different in terms of partnership quality, breastfeeding, mode of delivery, maternal education and depressive symptoms [19]. The pool of data showed us that, sexual function decreases during pregnancy and worsens as the pregnancy progresses. This process is influenced by many factors such as socio-cultural factors, age, parity, breastfeeding, depression, fatigue, sexual inactivity during the first trimester, postnatal body image, re-conception concerns, and concomitant urinary tract infections. There was no clear evidence that there is a relationship between the mode of delivery and changes in sexual function. Authors of this review pointed out that; sexual quality of life should be part of history due to possible sequelae of pregnancy and childbirth [20]. Symptoms of sexual dysfunction during pregnancy may have a negative impact on the quality of life of women and affect couples'relationships, therefore some interventions may be required, one thousand thirty-seven articles were taken into consideration in a previous review on this issue, four were selected for full-text reading, and two randomized trials (159 participants) were included. Based on this review, due to the heterogeneity between the studies, the results could not be combined. Based on the findings of this review, it is not possible to make a clear and conclusive recommendation on the effectiveness and safety of interventions used in the treatment of symptoms of sexual dysfunction in pregnancy [21].Therefore preventive measure have great importance on this issue, for this reason, risk factors have been assessed in the literature to introduce some measures, in the cross-sectional study including 286 pregnant women, being a partner at an advanced age, a history of miscarriage, a history of previous health problems and a high level of anxiety were found to be negative factors affecting sexual function. The authors of this study suggested that health professionals should be aware of a number of risk factors that may contribute to sexual dysfunction in pregnant women [22]. In another study, sexually active 246 pregnant women were included in this cross-sectional controlled study and a total of 210 non-pregnant women were used as controls. Groups were compared in terms of age, gestational age, incontinence, body mass index and obstetric history. Mean total FSFI scores were significantly lower in pregnant women than in non-pregnant women. In addition, the rate of sexual dysfunction in pregnant women was significantly higher than in non-pregnant women. However, no significant difference was found in the rate of sexual dysfunction in pregnant women compared to trimesters. In addition, gravidity and parity showed negative effects on sexual functions. However, the number of abortions did not affect sexual function. These data show that pregnancy sig- 
nificantly reduces sexual function in women [23]. This study by Aydin et al. was conducted on Turkish women and consistent with our results, pregnancy was found to be a risk factor for sexual dysfunction, no data regarding partner's sexual function was presented in the above-mentioned study.

Obesity and excess weight are increasing worldwide and can jeopardize the sexual functions of women. A previous study aimed to compare the sexual functions of normal and overweight women during pregnancy. A cross-sectional study on 105 overweight and 118 normal weights pregnant women in the 2nd and 3rd pregnancy trimesters was conducted. Female Sexual Function Index (FSFI) was used to assess sexual function. It was found that, in the second trimester, the mean total FSFI scores were similar to those of overweight and normal-weight women. While in the third trimester, the total FSFI scores of overweight women were significantly lower than those of normal-weight women. In the third trimester, the mean scores of overweight women in the areas of desire, arousal, lubrication, orgasm, and dyspareunia were significantly lower. The authors of this study concluded that overweight women in the third trimester of pregnancy had weaker sexual functions compared to normal-weight women [24]. No difference was determined between pregnant and nonpregnant groups and groups of women with and without $\mathrm{FSFI}<25(p>0.05)$ or with and without ARIZONA score $>11$.

Limitations of this study, it was a cross-sectional study and was not prospective, on the other hand, comparisons were made between different women, not with the same women before and after pregnancy and to the best of our knowledge, this is the first study, which assessed sexual function for both partners.

\section{CONCLUSIONS}

In conclusion, both female sexual function index and ARIZONA scores of their partners were found to be significantly different between groups of pregnant and nonpregnant Turkish women which indicated altered sexual function of couples during pregnancy.

\section{Acknowledgments}

The authors have nothing to declare. Informed consent was obtained from each participant. The study was approved by the institutional ethics committee. "All procedures performed in this study were in accordance with the ethical standards of the institutional research committee and with the 1964 Helsinki declaration and its later amendments or comparable ethical standards".

\section{REFERENCES}

1. Sexual Dysfunctions. Diagnostic and Statistical Manual of Mental Disorders, 5th Edition., doi: 10.1176/appi.books.9780890425596.125889.

2. Garcia S, Moreno S, Aponte H. Prevalence of sexual dysfunction in female outpatients and personnel at a Colombian hospital: correlation with hormonal profile. J Sex Med. 2008; 5(5): 1208-1213, doi: 10.1111/j.17436109.2007.00718.x, indexed in Pubmed: 18221292.

3. Cayan S, Akbay E, Bozlu M, et al. The prevalence of female sexual dysfunction and potential risk factors that may impair sexual function in Turkish women. Urol Int. 2004; 72(1): 52-57, doi: 10.1159/000075273, indexed in Pubmed: 14730166.

4. Sydow Kv. Sexuality during pregnancy and after childbirth. Journal of Psychosomatic Research. 1999; 47(1): 27-49, doi: 10.1016/s00223999(98)00106-8.

5. Orji EO, Ogunlola IO, Fasubaa OB. Sexuality among pregnant women in South West Nigeria. J Obstet Gynaecol. 2002; 22(2): 166-168, doi: 10.1080/01443610120113319, indexed in Pubmed: 12521698.

6. Astepe BS, Köleli I. A cross-sectional study of female sexual dysfunction among Turkish pregnant and nonpregnant women: correlation with hormone profile. The European Research Journal. 2018, doi: 10.18621 /eurj.432490.

7. Soykan A. The reliability and validity of Arizona sexual experiences scale in Turkish ESRD patients undergoing hemodialysis. Int J Impot Res. 2004 ; 16(6): 531-534, doi: 10.1038/sj.ijir.3901249, indexed in Pubmed: 15175639

8. Rosen R, Brown C, Heiman J, et al. The Female Sexual Function Index (FSFI): a multidimensional self-report instrument for the assessment of female sexual function. J Sex Marital Ther. 2000; 26(2): 191-208, doi: 10.1080/009262300278597, indexed in Pubmed: 10782451.

9. Öksüz E, Malhan S. Reliability and validity of the female sexual function index in Turkish population. Sendrom. 2005; 17: 54-59.

10. Oksuz E, Malhan S. Prevalence and risk factors for female sexual dysfunction in Turkish women. J Urol. 2006; 175(2): 654-8; discussion 658, doi: 10.1016/S0022-5347(05)00149-7, indexed in Pubmed: 16407018.

11. Soykan A. The reliability and validity of Arizona sexual experiences scale in Turkish ESRD patients undergoing hemodialysis. Int J Impot Res. 2004; 16(6): 531-534, doi: 10.1038/sj.ijir.3901249, indexed in Pubmed: 15175639.

12. McCool ME, Zuelke A, Theurich MA, et al. Prevalence of Female Sexual Dysfunction Among Premenopausal Women: A Systematic Review and Meta-Analysis of Observational Studies. Sex Med Rev. 2016; 4(3): $197-$ 212, doi: 10.1016/j.sxmr.2016.03.002, indexed in Pubmed: 27871953.

13. Ninivaggio $C$, Rogers RG, Leeman $L$, et al. Sexual function changes during pregnancy. Int Urogynecol J. 2017; 28(6): 923-929, doi: 10.1007/s00192016-3200-8, indexed in Pubmed: 27889829.

14. Seven M, Akyüz A, Güngör $S$. Predictors of sexual function during pregnancy. J Obstet Gynaecol. 2015; 35(7): 691-695, doi: 10.3109/01443615.2015.1006596, indexed in Pubmed: 25710683.

15. Eryilmaz $G$, Ege $E$, Zincir $H$. Factors affecting sexual life during pregnancy in eastern Turkey. Gynecol Obstet Invest. 2004; 57(2): 103-108, doi: 10.1159/000075582, indexed in Pubmed: 14673220.

16. Erol B, Sanli O, Korkmaz D, et al. A cross-sectional study of female sexual function and dysfunction during pregnancy. J Sex Med. 2007; 4(5): 1381-1387, doi: 10.1111/j.1743-6109.2007.00559.x, indexed in Pubmed: 17651387.

17. Esmer AC, Akca A, Akbayir O, et al. Female sexual function and associated factors during pregnancy. J Obstet Gynaecol Res. 2013; 39(6): 1165-1172, doi: 10.1111/jog.12048, indexed in Pubmed: 23718891.

18. Pauleta JR, Pereira NM, Graça LM. Sexuality during pregnancy. J Sex Med. 2010; 7(1 Pt 1): 136-142, doi: 10.1111/j.1743-6109.2009.01538.x, indexed in Pubmed: 19845548.

19. Wallwiener $S$, Müller M, Doster $A$, et al. Sexual activity and sexual dysfunction of women in the perinatal period: a longitudinal study. Arch Gynecol Obstet. 2017; 295(4): 873-883, doi: 10.1007/s00404-017-4305-0, indexed in Pubmed: 28251311.

20. Yeniel AO, Petri E. Pregnancy, childbirth, and sexual function: perceptions and facts. Int Urogynecol J. 2014; 25(1): 5-14, doi: 10.1007/s00192-0132118-7, indexed in Pubmed: 23812577.

21. Ribeiro MC, Nakamura MU, Torloni MR, et al. Treatments of Female Sexual Dysfunction Symptoms during Pregnancy: A Systematic Review of the Literature. Sex Med Rev. 2014; 2(1): 1-9, doi: 10.1002/smrj.18, indexed in Pubmed: 27784539.

22. Seven M, Akyüz A, Güngör S. Predictors of sexual function during pregnancy. J Obstet Gynaecol. 2015; 35(7): 691-695, doi: 10.3109/01443615.2015.1006596, indexed in Pubmed: 25710683.

23. Aydin M, Cayonu N, Kadihasanoglu M, et al. Comparison of Sexual Functions in Pregnant and Non-Pregnant Women. Urol J. 2015; 12(5): 2339-2344, indexed in Pubmed: 26571317.

24. Ribeiro MC, Nakamura MU, Torloni MR, et al. Maternal overweight and sexual function in pregnancy. Acta Obstet Gynecol Scand. 2016; 95(1): 45-51, doi: 10.1111/aogs.12796, indexed in Pubmed: 26456082. 